\title{
Improvement of termite resistance, dimensional stability and mechanical properties of pine wood by paraffin impregnation
}

\author{
Bruno Esteves $^{1}$, Lina Nunes ${ }^{2}$, IdAlina Domingos ${ }^{1}$ AND Helena PereirA ${ }^{3}$ \\ ${ }^{1}$ Polytechnic Institute of Viseu, Centre for the Study of Education, Technologies \\ and Health (CI\&DETS), Portugal \\ ${ }^{2}$ National Laboratory for Civil Engineering (LNEC), Structures Department. \\ Timber Structures Division, Lisbon, Portugal \\ ${ }^{3}$ School of Agriculture, University of Lisbon, Forest Research Centre (CEF), \\ Portugal
}

Email: bruno@demad.estv.ipv.pt

Fax: 0351232424651

Phone: 0351-232480645 


\section{Abstract}

Paraffin has been used throughout the ages as surface protection of wood but its use by impregnation to improve wood resistance to biodegradation is recent. This study determines the main improvements on wood properties with paraffin impregnation. Healthy Pinus pinaster Ait. wood was impregnated with paraffin at different levels, using a hot-cold process. Weight gain, equilibrium moisture content and dimensional stability (ASE) at $35 \%$ and $65 \%$ relative humidity, termite durability against Reticulitermes grassei (Clément), bending strength, bending stiffness (MOE) and Janka hardness were determined. Density increased from 0.57 to 0.99, ASE ranged between $38-96 \%$ and $16-71 \%$ for respectively $35 \%$ and $65 \%$ relative humidity. Equilibrium moisture content decreased from $9.9 \%$ and $12.0 \%$ to $0.8 \%$ and $3.6 \%$ for $35 \%$ and $65 \%$ relative humidity. Termite durability improved from level 4 to level 3 of attack and higher termite mortality was found in treated wood (52\% against $17 \%)$. Bending strength (MOR) increased with paraffin weight gain, reaching a 39\% increase. MOE also increased, by about $13 \%$ for wood with a weight gain around $80 \%$. Janka hardness increased significantly, reaching about $40 \%$ for wood with $80 \%$ weight gain. Paraffin impregnated wood has improved properties of equilibrium moisture, dimensional stability and density, bending strength and Janka hardness, and resistance against termites.

Keywords: Mechanical properties, modified wood, paraffin impregnation, Pinus pinaster, termites.

\section{Introduction}

Environmental concerns about the use of dangerous chemicals for wood protection have led to an increase in research on processes to improve properties of less noble and durable woods without the use of chemicals or with less harmful chemicals. Several wood modification processes have reached commercialization, mainly those based on heat treatment, like Thermowood ${ }^{\circledR}$, Plato ${ }^{\circledR}$ or Perdure ${ }^{\circledR}$, on chemical modification, like acetylation (Accoya®) or DMDHEU (Belmadur®), and impregnation by furfurylation (Kebony®). Although chemical modification and impregnation use chemicals, to be considered a wood modification these have to be harmless to the environment (Hill 2006). The main difference between these processes is that in chemical modification there are new chemical bonds that are responsible for the improvements, while in impregnation, although there might be some new chemical bonds, they are not responsible for 
the improvements. Wood modification processes are mainly focused on the improvement of resistance against biodegradation, dimensional stability and resistance against ultraviolet radiation (Esteves and Pereira 2009; Rowell 2006).

Paraffin is considered a harmless chemical, highly hydrophobic and commonly used has a water repellent to prevent water uptake, but its use by impregnation to improve wood resistance to biodegradation is recent . Scholz et al. (2010) studied the efficacy of distinct waxes, including paraffin, impregnated in Scots pine sapwood (Pinus sylvestris L.) against termites and concluded that waxes reduced termite damage, without preventing it. Nevertheless wax-impregnated pine sapwood showed, according to EN 117, a $100 \%$ termite mortality rate. The treatment with paraffin resulted in a good resistance against Reticulitermes banyulensis while amide wax treated beech wood sustained less 5\% mass loss against Coptotermes. acinaciformis and Mastotermes darwiniensis. The amide wax-impregnated beech wood showed excellent results in the field test but for impregnated pine sapwood only a moderate effect could be achieved in the laboratory test. No further studies could be found on paraffin impregnated wood but several studies were done with other waxes.

Lesar et al. (2009) combined boric acid with montan wax emulsion to improve boric acid fixation and performance against wood decay fungi, The results showed that they acted synergistically against the tested wood decay fungi and that with wax $50 \%$ lower boric acid retentions were needed to achieve sufficient protection against wood rotting fungi was and with less boron leaching from the impregnated specimens. Lesar et al. (2011) impregnated wood with several waxes and concluded that they reduced moisture absorption by wood subjected to accelerated weathering and restricted wood photodegradation . Lesar and Humar (2010) treated beech (Fagus sylvatica) and Norway spruce (Picea abies) wood with five water emulsions (montan wax, polyethylene, ethylene copolymer and oxidized polyethylene wax) and tested them against white rot, brown rot and blue stain fungi. The treated specimens had reduced water content and were more resistant to wood decay fungi although the treatments did not improve resistance to blue stain fungi. 
The adhesion of montan ester wax to wood was studied by Kurt et al. (2008) who concluded that with PVAc and MF adhesives, dry tensile shear strengths of waxtreated specimens were in a range comparable to those of untreated wood, but under wet conditions the strength values of wax-treated wood were significantly lower.

The colonization of wax impregnated pine sapwood (Pinus sylvestris L.) and beech (Fagus sylvatica L.) by blue stain fungi and their hyphal migration within the treated wood was investigated by Scholz et al. (2011). The treatment did not eliminate the fungal growth on the surface but there was a lower occurrence of hyphae inside the wax-treated wood, proving that blue stain fungi grew mainly near the cross-cut end of the board as well as in empty spaces such as microcapillaries, cell lumina of parenchyma tissue or other wax free zones of treated wood.

\section{Experimental}

\section{Treatment}

All the samples used in the tests were cut from a Pinus pinaster Aiton board without knots or other singularities. The treatment of pine wood by paraffin impregnation was made by a hot and cold process. This process is commonly used for some small companies without any pressurized vessels and in the case of this study allowed to combine a heat treatment with paraffin impregnation to determine if the utilization of a higher temperature bath is advantageous. The treatment consists of a lower temperature bath followed by a higher temperature bath with preservative solution. The pressure created by the temperature difference impels the liquid into the wood. The process was modified to allow the utilization of a paraffin bath. The paraffin used was Panreac Paraffin M.P. $51-53^{\circ} \mathrm{C}$ pellets. To determine the best conditions for the treatment, different temperatures and duration in the bath were tested. The temperature of the hot bath was $140^{\circ} \mathrm{C}$, $170^{\circ} \mathrm{C}$ and $180^{\circ} \mathrm{C}$ and of the cold bath $70^{\circ} \mathrm{C}$. Six sets of conditions were used as summarised in table 1 . Three sapwood samples with $10 \%$ equilibrium moisture content were tested for each treatment. 
Table 1 Temperatures and duration in the hot and cold baths for the different experiments

\begin{tabular}{cccccccc}
\hline & Sample & A & B & C & D & E & F \\
\hline \multirow{3}{*}{ Hot bath } & Temp $\left({ }^{\circ} \mathrm{C}\right)$ & 140 & 140 & 170 & 180 & 180 & 180 \\
& Time (min) & 120 & 120 & 120 & 120 & 240 & 240 \\
& Temp $\left({ }^{\circ} \mathrm{C}\right)$ & 70 & 70 & 70 & 70 & 70 & - \\
Cold bath & Time (min) & 30 & 120 & 30 & 30 & 30 & - \\
\hline
\end{tabular}

\section{Weight gain}

For the determination of the weight gain it was assumed that after the treatment the moisture was approximately zero. This had to be done since by the method used (hot cold process) it is very difficult to determine the amount of paraffin evaporated and the amount actually impregnated on wood by simply calculating the paraffin consumption. Nevertheless it has been proven before that after the treatment at high temperatures equilibrium moisture content is approximately zero.

\section{Equilibrium moisture content and dimensional stability}

The samples for equilibrium moisture and dimensional stability were cubic with $20 \times 20 \times 20 \mathrm{~mm}^{3}$, and well-defined tangential, radial and longitudinal sections.

The initial equilibrium moisture content was determined and used to calculate the dry weight. After the treatment, treated and untreated dry samples were weighed and their dimensions measured in all directions with a digital caliper $( \pm 0.01 \mathrm{~mm})$.

Afterwards the samples were kept in a conditioned room at $35 \%$ relative humidity $(\mathrm{RH})$ and $20^{\circ} \mathrm{C}$ until reaching a constant weight. When this was achieved the samples were weighted and measured once more. After that, the same procedure was done for wood conditioned at $65 \% \mathrm{RH}$ and $20^{\circ} \mathrm{C}$. The equilibrium moisture content at $35 \%$ and $65 \%$ relative humidity was determined with and without the paraffin weight gain as:

$\mathrm{EMC}=($ Wet sample mass-Dry sample mass $) /$ Dry sample mass $\times 100$

The dimensional stability of the treated samples was calculated in all directions between $35 \%$ or $65 \%$ relative humidity and the dry condition using the 
an Anti-Swelling Efficiency (ASE) method proposed by Stamm (1956) and presented in (Esteves et al. 2007b). ASE gives the shrinking difference between treated and untreated samples calculated in percent. Density was determined on both environments as mass/volume. Three replicates were tested for each treatment.

\section{Mechanical properties}

The samples for the determination of bending strength, bending stiffness (MOE) and Janka hardness had approximately $20 \times 20 \times 360 \mathrm{~mm}^{3}$, (radial $\times$ tangential $\times$ longitudinal) and well-defined tangential, radial and longitudinal sections, without knots or other singularities and well-defined tangential, radial and longitudinal sections. The paraffin impregnation was made by the hot and cold process using a hot bath at $140^{\circ} \mathrm{C}$ during $2 \mathrm{~h}$ and cold bath at $70^{\circ} \mathrm{C}$ during 10 and $30 \mathrm{~min}$, and using oven dry and moist wood with $10 \%$ equilibrium moisture content to obtain different levels of impregnation. Five replicates were tested for each treatment. For the determination of the weight gain of moist samples it was assumed that after the treatment the moisture was approximately zero. The samples were weighted before and after the impregnation and their dimensions measured in all directions with a digital caliper $( \pm 0.01 \mathrm{~mm})$. Before mechanical tests the samples were kept in a conditioned room at $20^{\circ} \mathrm{C}$ and $65 \%$ relative humidity until equilibrium was achieved.

\section{Bending strength}

Bending strength and modulus of elasticity were determined by a three point bending test using a Servosis Universal machine. Measurements were made under a constant velocity of $40 \mathrm{kgf} / \mathrm{min}$. MOE and bending strength were determined according to the following equations from the standard NP 619:

$$
\operatorname{MOE}\left(\mathrm{N} / \mathrm{mm}^{2}\right)=\frac{\Delta F \times L^{3}}{\Delta x \times 4 \times b \times h^{3}}
$$

\footnotetext{
where $\frac{\Delta F}{\Delta x}$ is the slope of the elastic zone in $\mathrm{N} / \mathrm{mm}, \mathrm{L}$ is the arm length, $\mathrm{h}$ the height and $b$ the width all expressed in $\mathrm{mm}$.
}

Bending strength $(\mathrm{MPa})=\frac{3 F_{\text {máx }} \times L}{2 \times b \times h^{10 / 6}}$ 
where Fmáx is the load on rupture in $\mathrm{N}, \mathrm{L}$ is the arm length, $\mathrm{h}$ the height and $\mathrm{b}$ the width all expressed in mm.

\section{Janka Hardness}

Janka hardness was measured on the tangential surface according to the ISO 3350 (1975) standard with minor changes. The force used was the force required by a steel ball of $11.28 \mathrm{~mm}$ diameter to penetrate in wood up to a quarter of its diameter $(2.82 \mathrm{~mm})$, instead of half diameter as mentioned in the standard, due to the softness of Pinus pinaster wood.

\section{Termite resistance}

Wood treated using a hot paraffin bath at $140^{\circ} \mathrm{C}$ and a cold paraffin bath at $70^{\circ} \mathrm{C}$ was used to assess the termite resistance against Reticulitermes grassei Clément. The general procedure of EN117 (2005) was followed using colonies of 250 workers of $R$. grassei, collected from broken trees and stubs in a Pinus pinaster Ait. forest situated approximately at $25 \mathrm{~km}$ east of Lisbon, Portugal. The colonies were established in $500 \mathrm{ml}$ glass conical flasks with moisturised sand (Fontainebleau sand and water; 4:1 v/v) as substrate. Five paraffin impregnated replicates were placed in contact with the termites and the test was run for eight weeks at $25^{\circ} \mathrm{C} \pm 2{ }^{\circ} \mathrm{C}$ and $80 \% \pm 5 \%$ relative humidity. Pinus pinaster untreated wood specimens with the same dimensions were also included as virulence controls.

\section{Results and discussion}

\section{Treatment}

Paraffin impregnated the wood and the samples increased their weight in values that depended on the treatment conditions (Table 2). The highest percentage of weight gain (WG) was obtained with the treatments A and B which correspond to $140^{\circ} \mathrm{C}$ for $2 \mathrm{~h}$ in a hot bath, and $30 \mathrm{~min}$ and $2 \mathrm{~h}$ in the cold bath (Table 2). The difference between these two treatments was very small, $86.6 \%$ against $86.9 \%$, proving that a longer duration in the cold bath does not significantly improve the impregnation into the wood. 
At temperatures above $140^{\circ} \mathrm{C}$ there was a lower overall weight gain probably resulting from a combined and contradictory effects of some mass loss due to thermal degradation and some weight gain due to paraffin impregnation. Additionally the formation of gaseous by-products formed during the heat treatment might limit the paraffin penetration into the wood. It is well known that pine wood degradation with heat starts at temperatures higher than $100^{\circ} \mathrm{C}$ (Belville 1982) but significant mass loss only occurs at temperatures higher than $140^{\circ} \mathrm{C}$ (Órfão et al 1999). Esteves et al (2008) reported a $0.5 \%$ mass loss for pine wood treated at $180^{\circ} \mathrm{C}$ for $2 \mathrm{~h}$ and $1.3 \%$ for $4 \mathrm{~h}$. Another reason for the lower weight gain at higher temperatures might be the fast drying of wood which decreases the mass transfer velocity.

The treatments $\mathrm{D}$ and $\mathrm{C}$ that differed on the hot bath temperature showed different weight increase: in $\mathrm{C}$ about $78 \%$ increase, and in D around $70 \%$, both lower than in treatments A and B. The difference should be due to the higher temperature on D that led to a higher mass loss than in C. The same was true between treatments $\mathrm{D}$ and $\mathrm{E}$ where the difference is the time spent in the bath at $180^{\circ} \mathrm{C}$ (2h in $\mathrm{D}$ and $4 \mathrm{~h}$ in $\mathrm{E}$ ) with higher weight gain in the $\mathrm{D}$ treatment (70\%) than in the $\mathrm{E}$ treatment $(61 \%)$ that might be due to the increased mass loss by thermal degradation in the longer duration treatment.

Another reason for the differences in the results might be the assumption that all of the samples were dry at the end of the treatment, which may not be true, especially for wood treated at lower temperatures. Treatment F, using only a hot bath, shows that most of the weight gain is done in the cold bath since even with 4 $\mathrm{h}$ in the hot bath the weight gain is around $16 \%$.

As a result of paraffin impregnation there was a significant increase in the wood density from 0.57 in the untreated samples, to between 0.65 (treatment F) and 0.99 (treatment B). This means that paraffin impregnated wood with a treatment similar to B will have a density close to the water density. The amount of paraffin in wood ranges from $88 \mathrm{~kg} / \mathrm{m}^{3}$ in treatment $\mathrm{F}$ to about $459 \mathrm{~kg} / \mathrm{m}^{3}$ for treatment B.

Table 2 Weight gain and density by paraffin impregnation under different treatment conditions

\begin{tabular}{llllllll}
\hline & & & & & \\
& & B & B & C & D & E & F \\
\hline Weight gain & Average & 86.6 & 86.9 & 78.1 & 69.7 & 61.4 & 16.0
\end{tabular}




\begin{tabular}{clllllll}
\hline$(\%)$ & Standev & 3.7 & 4.3 & 3.1 & 2.1 & 3.6 & 1.8 \\
& Average & 457 & 459 & 419 & 376 & 332 & 88 \\
$\left(\mathrm{~kg} / \mathrm{m}^{3}\right)$ & Standev & 8 & 4 & 7 & 15 & 8 & 14 \\
\hline \multirow{2}{*}{ Density } & Average & 0.98 & 0.99 & 0.95 & 0.92 & 0.88 & 0.65 \\
& Standev & 0,01 & 0,01 & 0,01 & 0,02 & 0,02 & 0,04 \\
\hline
\end{tabular}

\section{Equilibrium moisture content and dimensional stability}

The dimensional stability was determined to select the best treatment. Table 3 presents the dimensional stability as ASE at $35 \%$ and $65 \% \mathrm{RH}$ measured in the radial and tangential directions. ASE ranged between 38-96\% and 16-71\% for respectively $35 \%$ and $65 \% \mathrm{RH}$. The best anti-swelling efficiency (ASE) was obtained for a combined treatment at $180^{\circ} \mathrm{C}(4 \mathrm{~h})$ and $61 \%$ paraffin WG (treatment E) where $\mathrm{ASE}_{35 \%}$ was $89 \%$ and $96 \%$ and $\mathrm{ASE}_{65 \%}$ was $66 \%$ and $59 \%$ in radial and tangential directions, respectively. The results for wood treated at $140^{\circ} \mathrm{C}$ were not much lower with an $\mathrm{ASE}_{35 \%}$ around $80 \% \mathrm{ASE}_{65 \%}$ between $40-60 \%$.

These treatments present considerable better results than the results reported by Esteves et al. (2007b) with Pinus pinaster wood heat treated in an autoclave at temperatures between $190-210^{\circ} \mathrm{C}$ during $2-12 \mathrm{~h}$ with $\mathrm{ASE}_{35 \%}$ ranging from $27-57 \%$ and $39-63 \%$ for radial and tangential directions respectively.

The treatments at $180^{\circ} \mathrm{C}$ (D-E) were better than the treatments at $140^{\circ} \mathrm{C}$ (A-B), especially at higher relative humidity $\left(\mathrm{ASE}_{65 \%}\right)$. These results show that the improvements in dimensional stability are due not only to paraffin impregnation but probably also due to the heat treatment. Esteves et al. (2008) reported an improvement on dimensional stability between $40-60 \%$ for wood treated at $180^{\circ} \mathrm{C}$ during $2-4 \mathrm{~h}$. Tjeerdsma et al. (1998) referred that chemical changes due to heat treatment result in higher lignin reactivity which leads to the formation of several crosslinks that are responsible for increasing the dimensional stability because, since the molecule becomes less elastic, the cellulose microfibrils have less possibility to expand and absorb water. Treatment F, with only a low weight gain (16\%), achieved an $\mathrm{ASE}_{35 \%}$ similar to heat treated wood at $190^{\circ} \mathrm{C}$ for $12 \mathrm{~h}$ (39\%-radial, 56\% tangential) as reported by Esteves et al. (2007b) which confirms the synergetic effect of heat treatment and paraffin impregnation. Nevertheless the use of a higher temperature to improve dimensional stability might not be advisable since it will increase the treatment cost and decrease the 
wood mechanical properties, as stated before (Kim et al 1998; Esteves et al. 2007a; Esteves et al. 2007b; Korkut et al. 2008). Since wood impregnated with paraffin with the hot bath at $140^{\circ} \mathrm{C}$ presented good results, not significantly lower than wood impregnated at higher temperatures, this treatment was selected for the determination of mechanical properties and termite resistance.

Table 3 Dimensional stability as ASE at 35\% and 65\% RH measured in the radial and tangential directions. WG: weight gain in $\%$.

\begin{tabular}{llllll}
\hline & \multicolumn{3}{c}{ ASE35\% } & \multicolumn{2}{c}{ ASE65\% } \\
& WG & Rad35 & Tang35 & Rad65 & Tang65 \\
\hline A & 87 & 84 & 79 & 45 & 42 \\
B & 87 & 87 & 90 & 41 & 61 \\
C & 78 & 82 & 78 & 54 & 55 \\
D & 70 & 80 & 86 & 52 & 71 \\
E & 61 & 89 & 96 & 66 & 59 \\
F & 16 & 38 & 57 & 18 & 16 \\
\hline
\end{tabular}

Figure 1 presents the equilibrium moisture content versus the weight gain for untreated wood and for treatments A to F, excluding and including paraffin. Equilibrium moisture content decreased drastically due to the treatment from $9.9 \%$ and $12.0 \%$ to $0.8 \%$ and $3.6 \%$ for $35 \%$ and $65 \%$ relative humidity (Figure 1 ). If we include paraffin in the calculations, equilibrium moisture content is even lower reaching about $0.5 \%$ and 2.1 for $35 \%$ and $65 \%$ relative humidity. Nevertheless it should be mentioned that since it was assumed that equilibrium moisture content was approximately zero after the treatment, and this is not necessarily true, these equilibrium moisture content may be somewhat higher but surely much smaller than the content for untreated wood.

There are no significant differences between the equilibrium moisture content of treatments $\mathrm{A}$ to $\mathrm{E}$, while treatment $\mathrm{F}$ presented significant higher equilibrium moisture content, around $3.7 \%$ and $7.5 \%$ for $35 \%$ and $65 \% \mathrm{RH}$. However treatment D presents the higher equilibrium moisture content.

Comparing equilibrium moisture content of wood impregnated with paraffin with heat treated wood, paraffin impregnation attains better results. Esteves et al. (2007b) reported equilibrium moisture contents of heat treated wood at $190-210^{\circ} \mathrm{C}$ and $2-12 \mathrm{~h}$ ranging from $4-6 \%$ and $7-10 \%$. These results 
support the decision to select the treatment at $140^{\circ} \mathrm{C}$ for the determination of mechanical properties and termite resistance.

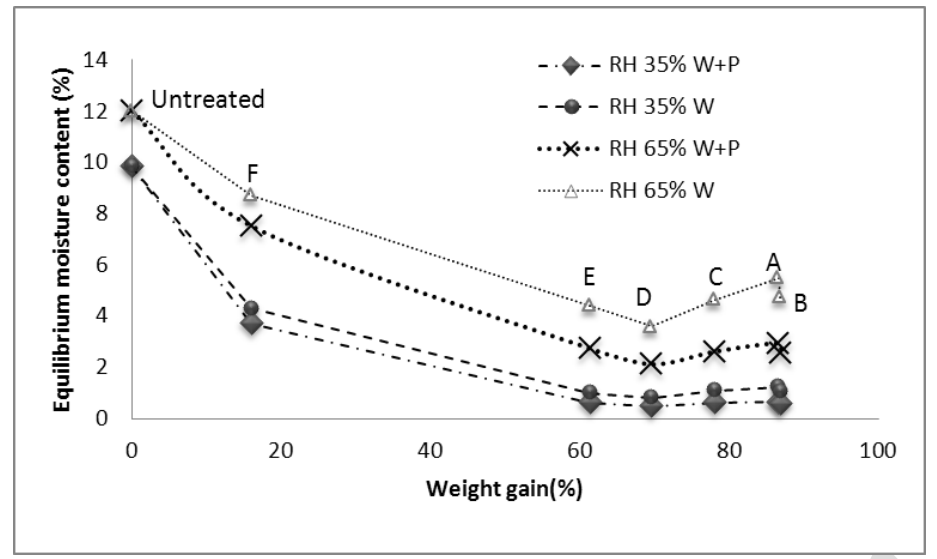

Fig. 1 Equilibrium moisture content vs paraffin weight gain. W-Wood, (W+P)-wood+paraffin

\section{Bending strength}

The samples for mechanical tests were impregnated using a hot bath at $140^{\circ} \mathrm{C}(2 \mathrm{~h})$, a cold bath at $70^{\circ} \mathrm{C}(10 \mathrm{~min}$ and $30 \mathrm{~min})$ and dry and wet samples. There was no significant difference between the treatments with $10 \mathrm{~min}$ and 30 min, showing that $10 \mathrm{~min}$ in the cold bath is sufficient to attain full impregnation. There was a significant difference however between dry and wet samples with dry samples presenting a weight gain of approximately $50 \%$ and wet samples of $85 \%$. This means that wet samples should be used to obtain full impregnation.

Figures $2 \mathrm{a}$ and $2 \mathrm{~b}$ present the bending stiffness (MOE) and bending strength (MOR) for untreated and paraffin impregnated pine wood at $140^{\circ} \mathrm{C}(2 \mathrm{~h})$ in relation to paraffin weight gain.

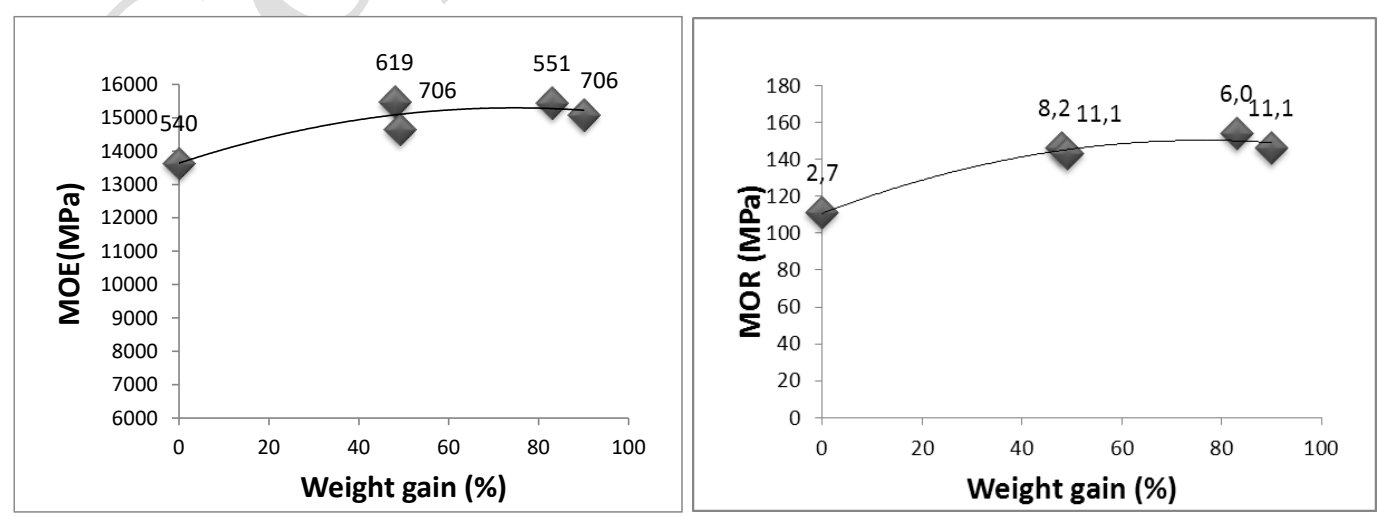

Fig. 2 MOE (a-left) and MOR (b-right) of untreated and treated wood in relation to weight gain. Standard deviation over the points

MOE increased slightly with the increase in paraffin weight gain reaching 
about $13 \%$ increase for $80 \%$ weight gain. This increase does not occur for other wood modifications where MOE is unaltered or even decreases with the treatment. For example, furfurylated pine wood presented similar MOE for untreated and treated wood (Esteves et al. 2010) while for heat treated pine wood Esteves et al. (2007b) reported a 7\% decrease.

The bending strength increased more than the bending stiffness, reaching $39 \%$ increase for wood with a weight gain around $80 \%$. This increase is much higher than that obtained with other wood modifications. Esteves et al. (2010) presented a slight increase (6\%) for furfurylated pine wood, while Esteves et al. (2007b) reported a decrease of more than $30 \%$ for heat treated pine wood.

Since paraffin impregnation leads to an increase in mechanical properties, mainly in bending strength, a combined treatment using paraffin impregnation and a heat treatment might allow the production of a material with higher dimensional stability and without significant loss of mechanical strength. Nevertheless paraffin impregnation alone presents very good results and the use of a higher temperature will not improve significantly the resulting material. 


\section{Janka Hardness}

Figure 3 presents the hardness for untreated, heat treated $\left(190^{\circ} \mathrm{C}-12 \mathrm{~h}\right)$ and paraffin treated wood with $49 \%$ and $83 \%$ weight gain. Hardness increased with paraffin impregnation and the increase was proportional to weight gain. For wood with $83 \%$ weight gain, hardness increased more than $39 \%$. In contrast, a heat treatment significantly decreased wood hardness by $27 \%$ in relation to untreated wood.

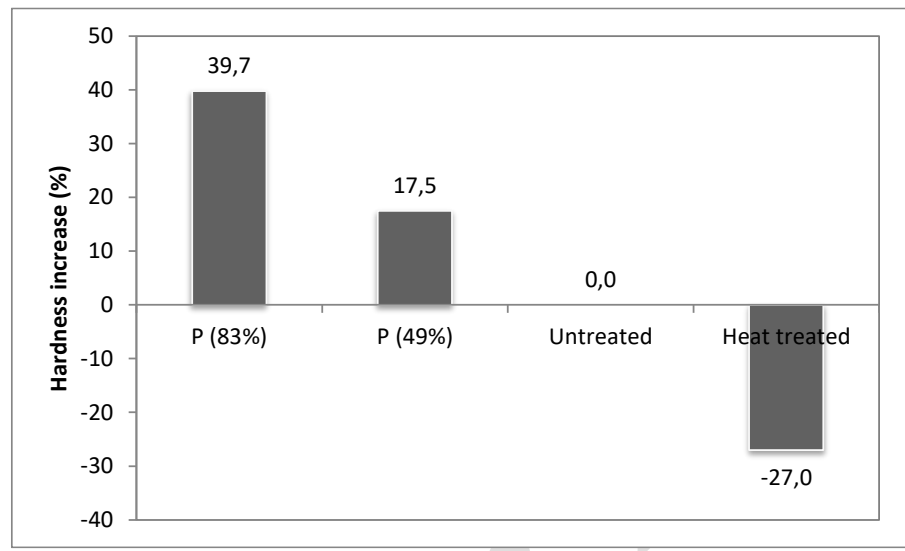

Fig. 3 Hardness of untreated and treated wood

This increase in bending strength, bending stiffness and hardness for paraffin impregnated wood is important because it might allow the utilization of treated pine wood in more demanding applications.

\section{Termite Resistance}

As regards the resistance towards termite degradation (Table 4), it was found that although paraffin impregnated wood was still attacked by $R$. grassei termites, the durability improved from level 4 to level 3 of attack. The paraffin impregnated wood also presented higher termite mortality (52\%) against $17 \%$ of untreated controls. These results are generally in agreement with those presented by (Scholz et al. 2010) with paraffin impregnated wood against $R$. banyulensis although these authors reported a higher decrease on the level of attack and a $100 \%$ termite mortality after the tests. Since different termite species were used, different reactions to treated wood are to be expected.

The level of attack on pine wood was 4 for untreated and heat treated wood, which means that these samples suffered a strong attack. All the samples of heat treated wood and without treatment showed the same level of attack. Several 
tunnels were observed in all of the samples, some of them where quite destroyed (Fig 4).

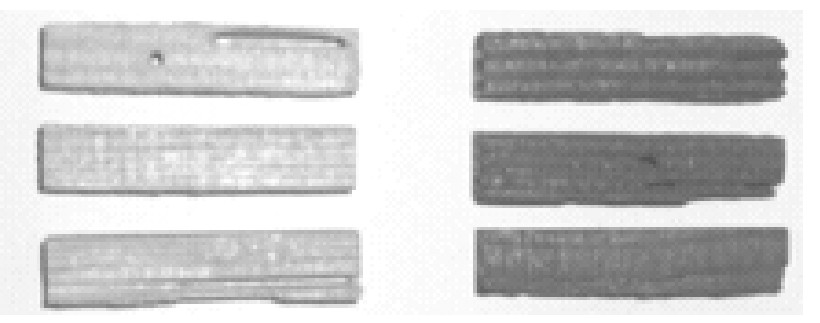

Fig. 4 Termite tunnelling on untreated (left) and heat treated wood (right)

Although the level of attack on pine wood was similar for heat treated and untreated samples, the survival of termites was lower for the heat treated samples, being on average $90.2 \%$ and $81.5 \%$ for wood with and without heat treatment, respectively. The improved resistance against termite attack for paraffin impregnated wood might be an advantage in relation to other wood modifications such as heat treatment. It is a known fact that the heat treatment improves the resistance against rot fungus but as proven here has a negligible effect on termite resistance.

Table 4 Mortality and attack grade of termites

\begin{tabular}{|c|c|c|c|}
\hline$\Omega$ & Sample & Grade & $\begin{array}{c}\text { Survival } \\
\%\end{array}$ \\
\hline \multirow{3}{*}{$\begin{array}{l}\text { Untreated } \\
\text { Pine }\end{array}$} & 1 & 4 & 94,0 \\
\hline & 2 & 4 & 81,3 \\
\hline & 3 & 4 & 95,3 \\
\hline \multirow{6}{*}{$\begin{array}{l}\text { Heat treated } \\
\text { pine }\end{array}$} & Average & 4,0 & 90,2 \\
\hline & 1 & 4 & 96,7 \\
\hline & 2 & 4 & 68,0 \\
\hline & 3 & 4 & 83,3 \\
\hline & 4 & 4 & 70,7 \\
\hline & 5 & 4 & 88,7 \\
\hline & Average & 4.0 & 81.5 \\
\hline \multirow{6}{*}{$\begin{array}{c}\text { Paraffin } \\
\text { impregnated } \\
\text { pine }\end{array}$} & 1 & 3 & 47.3 \\
\hline & 2 & 3 & 48.0 \\
\hline & 3 & 3 & 65.3 \\
\hline & 4 & 2 & 17.3 \\
\hline & 5 & 4 & 62.0 \\
\hline & Average & 3.0 & 48.0 \\
\hline
\end{tabular}




\section{Conclusions}

Paraffin impregnated pine wood had lower equilibrium moisture content, higher dimensional stability and density, and a higher resistance against Reticulitermes grassei termites in comparison to untreated wood. The treatment also increased the main mechanical properties of bending strength, bending stiffness and hardness in proportion to the paraffin weight gain. A paraffin impregnation treatment might allow the utilization of pine wood in more demanding applications thereby increasing its intrinsic value.

\section{Acknowledgements}

The authors would like to thank the Portuguese Foundation for Science and Technology (FCT) through projects PEst-OE/CED/UI4016/2014 and Pest-OEAGR-UI0239-2013, and the Center for Studies in Education, Technologies and Health (CI\&DETS).

\section{References}

Belville P. (1982) Modélisation de la cinetique de pyrolyse de particules de bois de taille importante et du bilan matiere de la gazeification à l'oxygene pur, Thesis Université de Compiégne, France

Esteves BM, Pereira H (2009) Wood modification by heat treatment: A review. BioResources 4:340-404.

Esteves B, Domingos I, Pereira H (2007a) Improvement of technological quality of eucalypt wood by heat treatment in air at 170-200 degrees C. Prod J $57: 47-52$.

Esteves B, Marques AV, Domingos I, Pereira H (2007b) Influence of steam heating on the properties of pine (Pinus pinaster) and eucalypt (Eucalyptus globulus) wood. Wood Sci Technol 41:193-207. doi: 10.1007/s00226006-0099-0

Esteves B, Domingos I, Pereira H (2008) Pine wood modification by heat treatment in air. BioResources 3:142-154.

Esteves B, Nunes L, Pereira H (2010) Properties of furfurylated wood (Pinus pinaster). Eur J Wood Wood Prod. doi: 10.1007/s00107-010-04804 
Kim, G., Yun, K., and Kim, J. (1998). "Effect of heat treatment on the decay resistance and the bending properties of radiata pine sapwood," Material und Organismen 32(2), 101-108.

Korkut, S., Akgü, M., and Dündar, T. (2008). "The effects of heat treat0ment on some technological properties of Scots pine (Pinus sylvestris L.) wood," Bioresour. Technol. 99, 1861-1868.

Kurt R, Krause A, Militz H, Mai C (2008) Hydroxymethylated resorcinol (HMR) priming agent for improved bondability of wax-treated wood. Holz Als Roh- Werkst 66:333-338. doi: 10.1007/s00107-008-0265-1

Lesar B, Humar M (2010) Use of wax emulsions for improvement of wood durability and sorption properties. Eur J Wood Wood Prod 69:231-238. doi: 10.1007/s00107-010-0425-y

Lesar B, Kralj P, Humar M (2009) Montan wax improves performance of boronbased wood preservatives. Int Biodeterior Biodegrad 63:306-310.

Lesar B, Pavlič M, Petrič M, et al. (2011) Wax treatment of wood slows photodegradation. Polym Degrad Stab 96:1271-1278. doi: 10.1016/j.polymdegradstab.2011.04.006

Órfão J, Antunes F, Figueiredo J (1999) Pyrolysis kinetics of lignocellulosic materials- Three independent reactions model, Fuel 78: 349-358.

Scholz G, Adamopoulos S, Militz H (2011) Migration of blue stain fungi within wax impregnated wood. IAWA J-Int Assoc Wood Anat 32:88.

Scholz G, Militz H, Gascón-Garrido P, et al. (2010) Improved termite resistance of wood by wax impregnation. Int Biodeterior Biodegrad 64:688-693.

Stamm, A. (1956). Thermal degradation of wood and cellulose, Industry and Engineering Chemistry 48: 413-417

Tjeerdsma, B., Boonstra, M., Pizzi, A., Tekely, P., and Militz, H. (1998).

"Characterisation of thermaly modified wood: Molecular reasons for wood performance improvement," Holz Roh-Werkst 56, 149-153. 